\title{
Correction to: Synthesis of fluorescent carbon quantum dots (CQDs) through the mild thermal treatment of agro-industrial residues assisted by $\gamma$-alumina
}

\section{Paola Brachi ${ }^{1}$}

Published online: 15 November 2019

(C) Springer-Verlag GmbH Germany, part of Springer Nature 2019

\section{Correction to: Biomass Conversion and Biorefinery} https://doi.org/10.1007/s13399-019-00503-4

The original version of this article unfortunately contained a mistake. The presentation of Figs. $6 \mathrm{~b}$ and $7 \mathrm{~b}$ were incorrect. The corrected figures are given below.
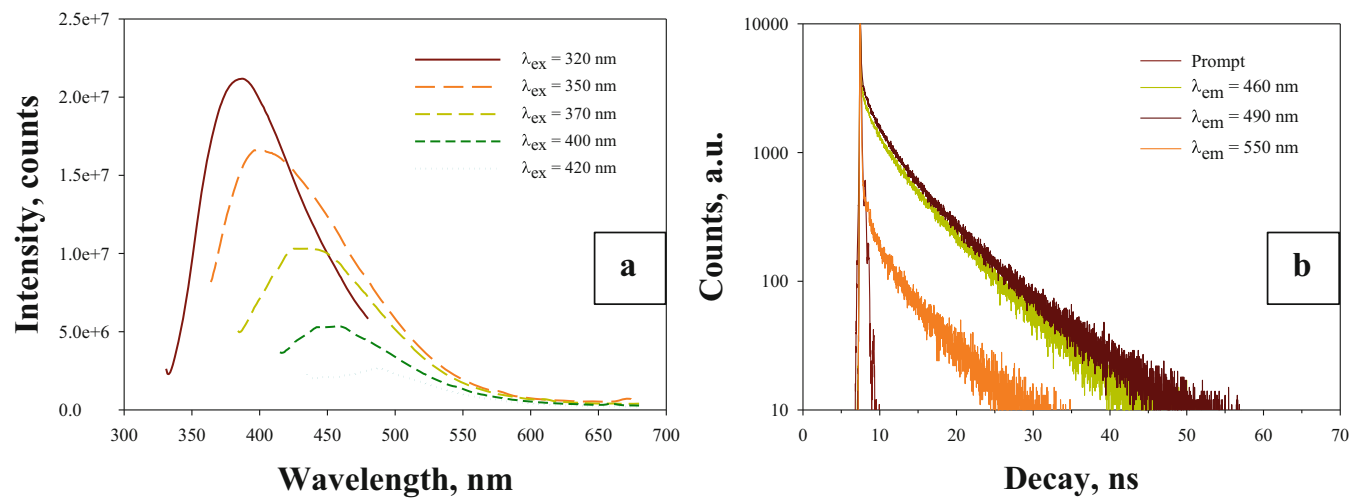

Fig. 6 Steady-state emission spectra collected at different excitation wavelengths (a) and decay curves recorded at different emission wavelengths (b) relative to the aqueous dispersion of SBP-based CQDs

The online version of the original article can be found at https://doi.org/ $10.1007 / \mathrm{s} 13399-019-00503-4$

Paola Brachi

p.brachi@irc.cnr.it

1 Institute for Research on Combustion, National Research Council, P.le Tecchio 80, 80125 Naples, Italy 
Fig. 7 (a) Pictures showing different solutions of SBP-based CQDs obtained via $\gamma$-alumina assisted synthesis performed at $300{ }^{\circ} \mathrm{C}$ under regular light (up; daylight lamp) and UV irradiation (down; $395 \mathrm{~nm}$ ), and (b) the UVvis absorption spectra (200-600 $\mathrm{nm}$ ) of the same solutions
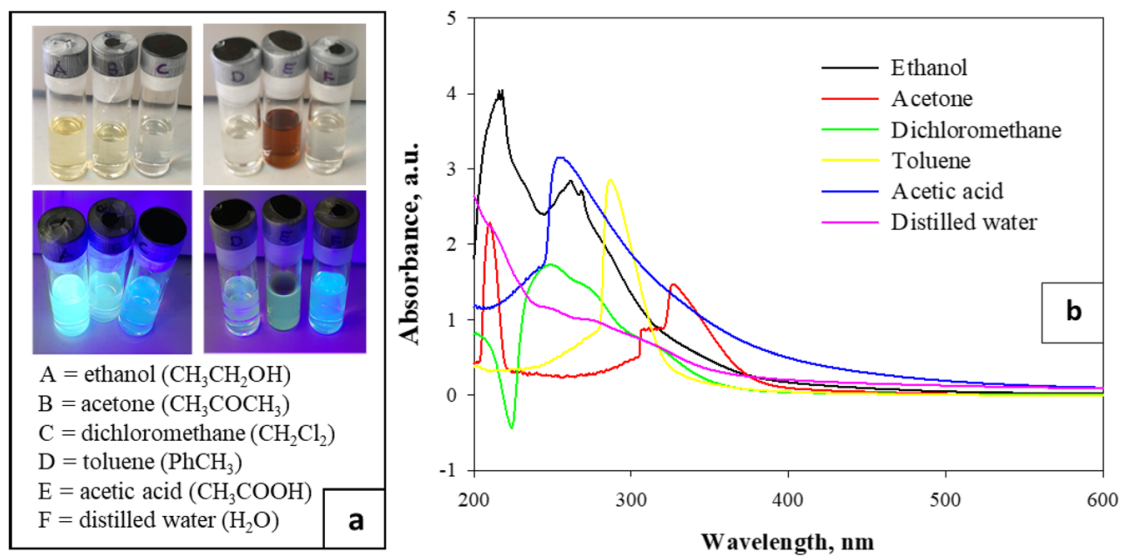

The original article has been corrected.
Publisher's note Springer Nature remains neutral with regard to jurisdictional claims in published maps and institutional affiliations. 